stone, professor of natural philosophy at King's, noted for his work on cable telegraphy. In 1927 the collection was transferred to the Science Museum.

There are about a thousand items in all, described in great detail and profusely photographed. Demainbray's instruments reflect his interest in teaching. There are pulley wheels and model engines (such as Vauloué's pile-driver used in the building of Westminster Bridge in 1738), model pumps, and optical models of short- and long-sightedness, the optics of the camera obscura, and 'Newton's doctrine of light and colour'.

Demainbray's instruments were good, but those of George III were fit for a king. These instruments cover the eighteenth century syllabus of pneumatics and mechanics. The centrepiece is a doublebarrelled air pump, based on the design of John Smeaton. The surviving accessories show what caught the public's imagination: brass Magdeburg hemispheres to demonstrate the power exerted by the weight of air; guinea and feather apparatus to demonstrate that they fall at the same rate in a vacuum; and a clockwork bell to demonstrate that sound does not travel in a vacuum.

The king's mechanics collection was also very comprehensive. This subject was made popular by the textbooks of s' Gravesande, Desaguliers and Nollet, which were used by Adams for the design of these pieces. However, this subject could never have been as popular as the spectacular lectures with the air pump, shown so graphically in Joseph Wright's An Experiment on a Bird in the Air Pump (exhibited in 1768). This painting was probably inspired by the lectures of James Ferguson. The air pump was the pièce de résistance of such scientific shows.

Also fascinating to the public was static electricity, which had only recently come of age. In the 1770 s the king sided with his court painter and amateur 'electrician', Benjamin Wilson, against the scientific establishment, deciding that ball-shaped lightning conductors were better than those terminating in sharp points. It is intriguing that there are no electrical instruments in the core of the George III Collection, although there are some fine specimens in the seventeenth and eighteenth century material deposited at Richmond Observatory, including a rare unsigned plate electrical machine from about 1770. This was purchased by the Prince of Wales (later George IV) in the 1780s from George Adams the Younger.

The George III Collection was only the latest in a long tradition of aristocratic collecting in Europe. The study of such material gives an added perspective to our understanding of the scientific activity of the period, augmenting literary sources. It provides specific insights into the manufacture of these devices, the relationship between instrument-making and scientific practice, and into the changing nature of such collections over time and the science teaching they represent. Such artefacts give us a tangible link with the past, and stimulate the imagination of those who may want to take up science as a career.

It is ironic that in the month of the publication of this lavish catalogue, the Science Museum has announced drastic cuts to its staff, which will lead to the closure of galleries and a loss of experts. In the future there may no longer be the in-house expertise to produce this kind of catalogue. This retrograde step makes the obvious pride expressed in the foreword about restoring the collection "to the prominence it so fully deserves" rather hollow. Perhaps this project will one day be seen as the Science Museum's swan song as it embraces the modern twin notions of interactive science centres and the public understanding of science. Undoubtedly these are worthy means of widening scientific awareness. It should be remembered, however, that historical collections, too, can be important in understanding modern science. But perhaps the present Science Museum management has more faith in the old proverb: 'Happy is the country that has no history'.

Willem Hackmann is at the Museum of the History of Science, Old Ashmolean Building, Oxford OX1 $3 A Z$, UK.

\section{Earth in motion}

\section{Paul Segall}

Fault Mechanics and Transport Properties of Rocks. Edited by Brian Evans and Teng-Fong Wong. Academic: 1992. Pp. 524. £45, $\$ 99$.

THIS volume arose out of a 1990 symposium held in honour of William F. Brace on his retirement after three-and-a-half decades at the Massachusetts Institute of Technology. His colleagues and former students have contributed papers that span four subject areas in which Brace made fundamental contributions.

The first section, on brittle failure of crustal rocks, contains papers on experimental studies of faulting. D. A. Lockner and others show how acoustic emissions can be used to map the formation of a new fault surface in a previously unfaulted sample. Other authors discuss fabric development in calcite gouges and the nature of the brittleductile transition in feldspar-rich rock. A study of the frictional strength of clay-rich gouges shows that these materials cannot explain the low strength of the San Andreas fault as determined by the absence of a heat-flow anomaly.

Papers on permeability and flow include G. J. Fischer's new method for computing permeability and storage capacity of rock samples. The method imposes a sinusoidal pressure variation on one end of the sample and relates the amplitude and phase of the pressure signal at the other end to the permeability and storage capacity. Theoretical papers cover permeability in anisotropic rocks and methods for relating hydraulic properties to digitized images of rock cross-sections. Two experimental papers discuss the growth of grain contacts by solution transfer in halite, and the effect of water and carbon dioxide on silicate melt migration through polycrystalline olivine.

The third section, on fracture characterization and physical properties of rock, contains five papers, including one by M. N. Toksöz and colleagues on the in situ characterization of fractures from vertical seismic profiling data. The method uses tube waves that are generated when a fracture, which intersects the borehole, is compressed by a passing seismic wave. The dip of the fracture can be related to the efficiency with which tube waves are generated by incident $P$ and SV waves. Two papers in this section report on field observations of joints in siltstones. There is a study of the effect of stress on remanent magnetization, and a study in which X-ray tomography is used to determine the distribution of oil and water in samples during measurements of resistivity.

The final section, on implication of rock mechanics for crustal tectonics, mainly contains theoretical studies, including an already frequently cited paper by J. R. Rice on the weakness of the San Andreas fault. The most obvious explanation for the weakness - high pore-fluid pressures - had previously been dismissed on the grounds that the pressures would hydraulically fracture the adjacent crust. This argument assumes that the state of stress in a mature fault is the same as that in the surrounding crust, but Rice shows how simple mechanical considerations indicate that this is unlikely. Rice's work has re-established high pore-fluid pressure as the most reasonable explanation. Another study in this section argues that creep closure of pores leads to high fluid pressures in the lower crust followed by natural hydrofacing, resulting in fluid pressure cyciing. Other papers address the state of stress on the active faults, and the emplacement of foreland thrust sheets.

The papers are of uniformly high quality and a few represent significant advances. The volume is a fitting tribute to Brace's career.

Paul Segall is in the Department of Geophysics, Stanford University, Stanford, California 94305, USA. 